\title{
A catástrofe e a precaução ${ }^{*}$
}

\section{La catastrophe et la précaution*}

\section{Catastopher and precaution*}

\author{
Jean-Pierre DUPUY**
}

O que a faz pensar que o perigo é gravissimo? François Guery [sobre o tema dos transgênicos]

Eu não sei se o perigo é gravissimo ou não, este é precisamente o problemal. Corinne Lepage

A sociedade industrial, fundamentada no desenvolvimento das ciências e das técnicas, parece estar descobrindo atualmente - e com que efervescência, com que confusão de pensamentos! - que ameaças graves, até mesmo gravíssimas, pesam sobre o seu futuro. Neste sentido, nossa ex-ministra do meio ambiente Corinne Lepage acaba de publicar um salutar grito de alerta em companhia do filósofo François Guery.

A extrema importância do assunto tratado, assim como a pertinência e a força de certas teses defendidas pelos autores, mereciam, entretanto, um tratamento infinitamente melhor que a conversa enfadonha e repetitiva mantida diante de um gravador, cuja transcrição resulta em um texto a que se ousa chamar de livro, que não deve ter sido (re)lido por ninguém dentro da cadeia editorial, nem pelos autores, nem pela diretora da coleção, nem pelos revisores das Presses Universitaires Françaises. ${ }^{2}$

Não tenho nenhuma prova para afirmar o que disse acima, mas esta é de longe, reconheçamos, a hipótese mais caridosa, a menos humilhante para as pessoas em questão, se levarmos em conta o tecido de horrores editoriais dos quais apresento aqui uma pequena amostra.

Assim, tome uma frase, inverta sujeito e verbo e concorde, por sua vez, o verbo com o seu complemento: "Nenhum estudo (...) surgiu para analisar os efeitos que poderiam ter (...) o recurso maciço aos OGM (...)" (p. 44). Invente conjugações inéditas e originais: "não se recorrereria a este tipo de ração"(p. 144); "patentieiam a torto e a direito (este "patentieiam" é tão bem modelado que os autores não resistem a empregá-lo várias vezes: p. 218 e $224 ;^{3}$ "um bilhão (de habitantes do planeta) não tem acesso a uma água suficientemente boa" (p.74).

\footnotetext{
* Publicado na Revista NSS, 2001, v. 9, n. 3, p. 53-58/0 2001 Editions... Todos os direitos reservados. Traduçào: Eduardo Nadalin - Professor de lingua Francesa do Departamento de Letras Estrangeiras Modemas da UFPR.

** Professor Grisé Escola Politécnica e Universidade de Stanford, Rua Descartes, 75.005, França. jpdupuy@poly.polyteclunicutefi

I Sobre la Politique de préc antion de Corimne Lepage e François Guely, Presses Universitaires Françaises (Puf), Paris 2001, Coll. "Questions actuelles". (N.A.), p. 49. 2 Presses Universitaires Françaises (Puf) - Editora francesa (N.T.)

3 Com sua estupidez mecânica, meu corretor ortográfíco e gramatical sublinha furriosamente de vermelho e de verde estas invenções lingüisticas, confundindo mençào e uso, o que ressalta ainda mais a impericia de seus companheiros humanos, os revisores das Presses Universitaires Françaises. (N.A.)
} 
Daria para se perguntar a partir de qual número de habitantes o verbo seria colocado no plural, talvez dois biIhões. Para certificar-se de que seu leitor o está acompanhando bem, repita, com algumas páginas de intervalo, parágrafos inteiros, palavra por palavra (p. 184 e 190). Para facilitar a tarefa deste mesmo leitor, chame, num momento, o grupo intergovernamental para a evolução do clima pelo seu nome e sigla em francês (p. 69), num outro momento pelos seu nome e sigla em inglês (p. 73), sem observar que se trata da mesma entidade. Sendo a energia um de seus temas prediletos, invente uma unidade de medida capaz de espantar os físicos, o kilow'at hora (p. 69). Para não deixar os químicos com ciúmes, chame o $\mathrm{CO}_{2}$ de "óxido de carbono".

Faça com que os pronomes pessoais correspondam a substantivos diferentes daqueles que você enuncia, principalmente quando isso permitir produzir efeitos cômicos. Assim: "há pessoas que estão novamente consumindo miolos e timo de vitela. A proibição não foi respeitada sob pretexto de que não estão mais thes dando ração animal. Portanto, não há mais perigo." (p. 1718). Uma análise gramatical simples permite inferir: Não se dá mais ração às pessoas. Vamos tomar fôlego! Sempre que possível, invente diálogos no estilo non-sense dos irmãos Marx, como se você quisesse entrar para o colégio de patafísica de Francis Blanche. Assim: F. Guery: "você suspeita que os OGM estejam na base de uma perturbação ecológica, como se se tratasse de um acidente. Exceto que, diferentemente de um acidente, é deliberado!" C. Lepage: "Claro, mas por quem e no interesse de quem?"(p. 55). Fale inglês para fazer bonito ou ser pretensioso, mas dê um jeito de fazer isto soar engraçado aos ouvidos dos nativos. "Assim, o desaparecimento do Golf Stream (sic) seria, certamente, uma grande catástrofe, principalmente para os jogadores de golfe!" (p. 81). Não poupe os pleonasmos e outras redundâncias, senão poderiam perguntar sobre o que você está falando. Assim: "a poluição genética, diferentemente de outras poluições, é a única (...) que é exponencial " ( $p$. 38). Realmente é muito difícil ser o único de sua espécie multiplamente. Não respeite absolutamente a ortografia dos nomes dos autores que você cita, eles poderiam ser identificados muito facilmente (Illitch por Illich, p. 177; Prygogine por Prigogine, p. 186; Kourilski por Kourilsky, uma dúzia de ocorrências entre as páginas 234 e 255, o que é o cúmulo, considerando-se o lugar que ocupa o relatório com o mesmo nome em qualquer discussão sobre o assunto etc.).

Mas não se preocupe, pois ninguém vai criticá-lo, nem mesmo os críticos que, louvando a sua produção (o que é um direito deles), irão deixar cuidadosamente de observar aos leitores em potencial a que eles estão expondo-se (o que é uma omissão deles). Eu tenho à disposição de quem quiser fazer uso, bom ou mau, uma lista de cerca de 200 barbarismos deste gênero que "poluem" este objeto editorial de quase 400 páginas.

Mas, por que insistir neste ponto? Simplesmente porque esta vergonha relaciona-se diretamente com o assunto tratado pelos autores, assunto este que tem um nome: respeito pelas coisas criadas, pelo mundo, pela vida, pelos seres. De fato, o respeito devido por um autor a seus leitores parece-me fazer parte disso. Mas talvez eu seja um defensor incorrigível lutando por uma coisa que já morreu: o livro. Em todo caso, o editor parece ter dito a si mesmo que as propostas de uma mulher atuando na politica devem sempre ser boas, fazendo com que o produto venda por uns três meses, tempo suficiente para que um outro livro do "mesmo calibre" o substitua nas estantes das livrarias.

Chega-se ao cúmulo quando se descobre que os dois "autores", uma ex-ministra do meio ambiente e o outro, um filósofo, demonstram uma ignorância dramática nas suas respectivas áreas de competência O princípio da precaução está evidentemente no centro de suas discussões. Acreditariam em mim se eu dissesse que a senhora Lepage parece não conhecer, não a definição, pela qual de qualquer forma nunca se deve começar, mas a caracterização formal intuitiva deste princípio, bem expressa pelo relatório Kourilsky-Viney nos seguintes termos: "a distinção entre risco potencial e risco comprovado constitui a distinção paralela entre precaução e prevenção. A precaução é relativa a riscos potenciais e a prevenção a riscos comprovados"? O relatório precisa: "As probabilidades não são da mesma natureza (no caso da precaução, trata-se da probabilidade de que a hipótese seja exata; no caso da prevenção, a periculosidade é estabelecida e trata-se da probabilidade do acidente." O risco potencial sendo, por sua vez, caracterizado como 
"risco de risco". Enfim, tudo se fundamenta na distinção entre um evento de que se conhece a distribuição das probabilidades (risco comprovado ao qual corresponde a prevenção) e um evento de que não se conhece a distribuição das probabilidades, mas para o qual, admitamos isso à maneira de Savage e de suas probabilidades subjetivas, é possível atribuir uma distribuição de probabilidades a esta de probabilidades desconhecidas (risco potencial ao qual corresponde a precaução). Aqui está uma distinção clássica em teoria da decisão, entre universo de risco e universo incerto, que remonta aos trabalhos de Keynes e de Knight nos anos de 1920. Ora, eis o que esta distinção se torna nas palavras da senhora Lepage: "A prevenção consiste em disponibilizar mecanismos destinados a combater um risco que se conhece, mas do qual ignora-se a probabilidade." (p. 52). Se relacionarmos o desconhecimento das probabilidades à prevenção, é de se perguntar o que restaria para a precaução, a não ser a neblina de Londres pintada por Turner ou, pior, o smogh que desde então a substituiu. De fato: "A precaução se refere a um risco do qual se ignora o perímetro, a importância, até mesmo a existência real." (lbid.) A senhora Lepage talvez ignore que conhecer a distribuição de probabilidades de um evento aleatório não significa saber se ele vai ocorrer ou não.

Quanto à filosofia, ela não é mais bem tratada do que a língua ou a lógica. Popper, "o imortal autor da Lógica da descoberta científica" (p. 41), é por várias vezes apresentado, glorificado por ser o inventor da "concepção moderna de ciência". Essa asserção poderia ser fortemente discutida, mas esta não é a questão aqui. De fato, quando se trata de explicar o critério de "falsificação", a senhora Lepage confunde-se dramaticamente, não sendo em nada apoiada pelo seu companheiro filósofo, acabando por cair, "plaft", assim como Sganarelle quando tenta demonstrar a Don Juan o seu erro, em um inevitável contra-senso: "a ausência de inocuidade não pode, como tal, ser provada" (p. 40). É verdade que quando se tem uma tripla negação - $\mathrm{a}$ ausência de uma ausência de nocividade - as coisas ficam confusas. A ausência de inocuidade, ou seja, a nocividade, pode ser provada, basta para isso exibir um só caso de nocividade. Evidentemente, dentro de um pensamento popperiano, é a inocuidade que não pode ser provada, já que para isso seria necessário pôr à prova, com um número infinito de experiências, a verdade de uma proposição de quantificador universal do tipo: qualquer que seja o caso $\mathrm{x}$, o produto considerado não é nocivo.

Eu poderia ainda evocar o utilitarismo, esta filosofia moral da "benevolência abstrata universal", para citar um de seus fundadores, que é confundida sistematicamente por M. Guery com uma psicologia do egoísmo interesseiro e mercantil, um outro grave contra-senso. A referência furtiva a Rawls não é menos caricatural. $\mathrm{O}$ cansaço me impede de continuar o exame das atrocidades que nos apresentam neste livro sem o menor constrangimento.

Por que então falar sobre este livro, poderiam perguntar-me, e não deixá-lo afundar irremediavelmente no pântano de livros efêmeros que são postos no mercado pelo simples fato de trazerem o nome de uma homem ou de uma mulher "da mídia"? Infelizmente, deste livro é preciso falar, sim. Pois há urgência e a senhora Lepage é um dos raríssimos membros da classe política que têm a coragem de dizer o que todos os outros calam, temendo, talvez, iniciarem uma onda de pânico. Pânico haverá de qualquer forma, e guerras e destruição em massa, como preço a se pagar por décadas do que ainda se ousa chamar de "crescimento". Se há crescimento, é um crescimento canceroso, um fenômeno de runaway, ${ }^{7}$ uma autodesregulação, uma reação "divergente", como se diz das centrais nucleares quando elas ficam fora de controle antes de iniciar uma explosão atômica. Sim, é preciso falar sobre isso, gritar aos quatro ventos, mesmo que sejam apenas gemidos que saem da boca de alguns vigilantes apavorados.

Nossos autores assumem plenamente uma atitude chamada atualmente, para melhor se destacar, de "catastrofista". "Dentro de 30 anos, nós iremos viver uma série de crises de toda natureza ligadas a questões de energia e mudanças climáticas, diz Corinne Lepage, sem que nenhuma medida que nós viéssemos a tomar hoje pudesse ter qualquer efeito". (p. 85). Em outra parte: "as conseqüências da doença da vaca louca serão cataclísmicas para os poderes públicos, bem como para o sistema em geral." (p. 90). E ainda; "Se nós pensarmos 
no destino da natureza do planeta condicionada pelo homem, um destino que nos contempla do futuro, é certo que experimentemos um sentimento misto de medo e de culpa; medo porque a previsão nos mostra realidades assustadoras; culpa porque somos conscientes de nosso papel na origem da determinação destas realidades."(p. $113 ;^{*}$ grifo meu). E a descrição da "vertigem existencial", "a percepção de participar de uma fuga não suscetível de ser controlada e, a fortiori, interrompida [...]. Uma máquina tecnológica louca, guiada unicamente pela sede de ir sempre mais e mais longe e de ser mais e mais rentável está em andamento..." (p. 177-178). Notam-se as referências constantes, não ao que se chama correntemente de "riscos", termo perfeitamente impróprio no caso em questão, mas àquilo que se apresenta como destino, fatalidade ou mesmo tragédia. A referência ao trágico está explícita nas palavras de Guery: "Caimos de nossa torre de marfim e descobrimos que consequiências impensáveis esperam por nós sem que tenhamos sido capazes de antecipá-las". (p. 198).

A influência do filósofo alemão Hans Jonas no livro é muito clara, e suas teses são evocadas várias vezes com deferência. Isto por si só já basta para distinguir nossos autores da maior parte daqueles que, hoje na França, falam e escrevem sobre o tema da precaução. Todos se sentem obrigados a se referir ao autor do "Princípio Responsabilidade" para melhor destacar que eles não navegam nas mesmas águas que ele. A "Política de precaução", ao contrário, pode ser lida como uma defesa e ilustração da posição jonassiana, na medida em que propõe uma postura filosófica e política diante das novas ameaças que despontam no horizonte da humanidade. Considero-me em total simpatia com aqueles que se dispõem a fazer isto. É justamente por isso que acho tão lamentável que os autores tenham faltado com rigor e seriedade ao ponto que o fizeram. É por demais tentador criticar o objetivo que eles propõen tratar, atacando a cópia desastrosa que eles depositaram nas mãos do público.

Como eu disse, o pensamento de Jonas seria "catastrofista" e tributário do que o próprio Jonas chama de uma "heurística do medo". É fato que, no "Princípio Responsabilidade", encontra-se o seguinte "mandamento": Nos as- suntos referentes a eventualidades de importância capital, dar um peso maior à ameaça do que à promessa, e (...) evitar perspectivas apocalípticas, mesmo sob preço de, eventualmente, perder assim realizações escatológicas." (p. 74). Em termos mais simples: "É preciso dar mais ouvidos à profecia de infelicidade do que à profecia de felicidade." (p. 73). Eu acredito que a legitimidade desta posição é passível de ser demonstrada e isso não em momentos de angústia e inquietação, mas com todos os recursos de uma cabeça fria. É racional hoje em dia ser catastrofista no sentido indicado pelo mandamento de Jonas. Há razões que justificam isso. Para criticar esta postura, caracterizam-na como obcecada pelo "cenário do pior". Corinne Lepage e François Guery contestam: “É (...) o non-sens da destruição (...) que implica a recorrência ao cenário do pior. (...). É precisamente a pertinência, ou mesmo a simples existência da possibilidade de um cenário do pior que pode e deve (...) guiar a reflexão e (a) ação." (p. 136). A fórmula é forte, ${ }^{10}$ mas seria preferível que ela fosse estruturada com argumentos racionais.

O próprio Jonas oferece dois argumentos, um ligado à filosofia moral e o outro à metafísica. O primeiro é que não descobrimos verdadeiramente o valor das coisas a que nos ligamos senão fixando-nos na perspectiva de perdê-las: "apenas a previsão da deformação do homem nos fornece o conceito do homem que permite, por sua vez, que possamos nos prevenir desta deformação", (p. 16), escreve o filósofo alemão. O segundo argumento, metafísico, toma a seguinte forma: "a profecia da infelicidade é feita para evitar que ela se realize; e zombar ulteriormente daqueles que eventualmente tenham se prevenido quanto ao perigo, lembrando-lhes de que o pior não aconteceu, seria o cúmulo da injustiça: pode ser que o disparate deles seja o seu mérito." (p. 233). Para sentir todo o peso paradoxal desta afirmação, é necessário, primeiramente, compreender que Jonas fala aqui de profecia no senso estrito, ou seja, a previsão do futuro tal qual ele se inscreve em nosso horizonte temporal. Não se trata de anunciar um acontecimento indesejável ou absolutamente detestável como se fosse o futuro, de forma que este anúncio, especificamente, faça com que

8 Relendo o texto, percebi que esta citaçào é, de fato, um empréstimo de Jonas. As aspas foram omitidas. Neste ponto, a negligência se torna plagio puro e simples. (N.A.)

9 Ed. Editions du Cerf, 1990. (N.A.)

IO É muito dificil citar literalmente este livro por ser muito improvável deparar-se com uma frase que nào esteja marcada por um barbarismo horrendo. (N.A.) 
isso não seja o futuro. Este procedimento é do âmbito da lógica da prevenção, é o discurso preventivo do tipo "Bison futé"." Com Jonas, estamos em uma metafísica totalmente diferente, em que a catástrofe inscrita no futuro como um destino nos saúda e nos "contempla", como escreve jocosamente o filósofo. Nossa responsabilidade paradoxal é fazer com que este futuro inevitável não se realize. Pensar nesta questão é um verdadeiro desafio para a filosofia, aqui somente salientado. Voltarei a este assunto na conclusão do texto.

Mas por que seria necessário pensar sobre coisas tão complexas, por que seria necessário associar as luzes do filósofo à capacidade de governar do político da forma como tenta este livro? Simplesmente, porque a presente situação nos mostra que o anúncio de catástrofes não vem produzindo nenhuma mudança sensivel, nem em nossa maneira de fazer as coisas, nem em nossa maneira de pensá-las. Mesmo quando são informados sobre alguma coisa, os povos do mundo "não acreditam no que eles já sabem" (é algo que nossa mente refuta porque nos dizemos que não é possível, (IIIPAGl: 2001, p.16)), da mesma maneira que nos é muito difícil, individualmente, acreditar naquilo que é a nossa maior certeza, que vamos morrer. Sobre o aquecimento do clima, diznos Corinne Lepage, "embora há 20 anos conheçamos perfeitamente o risco ao qual nos confrontamos, a verdade é que, estritamente, nada temos feito."(p. 70). Em março de 2001, o presidente Bush violou cinicamente a promessa que ele tinha feito a seu povo durante a campanha eleitoral, renunciando a reduzir, em seu país, as emissões de gás responsáveis pelo efeito estufa. Analistas políticos observaram que o presidente cedeu à pressão de deputados republicanos que fazem lobhying em favor das indústrias do petróleo e do carvão. A mesma observação valeria também para outras áreas, como por exemplo, a da insegurança alimentar. Não apenas o medo da catástrofe que está por vir - ninguém pode dizer hoje em dia que não haverá uma epidemia de doenças de príons de grande amplitude entre os homens - não tem nenhum efeito dissuasivo; não apenas a lógica econômica (aqui, os interesses do poderoso lobby agroalimentar) continua fazendo o que bem entende; mas nada se aprende.
A França não tirou estritamente nenhuma lição do caso do "sangue contaminado", já que ela bateu o triste recorde de ser o país europeu que, de 1993 a 1996, importou mais ração animal da Grã-Bretanha.

A catústrofe não é plausivel, este é o maior obstáculo. Como dar uma força dissuasiva ao medo da catástrofe, uma vez que não é absolutamente o caso atualmente? É precisamente com este fim que se deve construir uma heurística do medo. Poderão protestar contra isso, como o faz Catherine Larrère: '“' a profecia de infelicidade' (...) exclui toda a possibilidade de escolha (...). A escolha do cenário do pior impede todo o debate democrático: sob a ameaça da catástrofe iminente, não se saberia deliberar". ${ }^{12}$ Ora, existe um precedente, não ouso dizer um modelo, amplo, que mostra expressivamente que uma heurística do medo pode ser eficaz: o equilíbrio do terror, a dissuasão nuclear. Bernard Brodie, um dos mais inteligentes defensores daquilo que constitui a uma só vez o cúmulo da racionalidade e, como seu próprio nome o indica, da loucura humana, resumiu perfeitamente a lógica da política da "vulnerabilidade mútua" conhecida pelo nome de MAD (Mutually Assured Destruction), nos

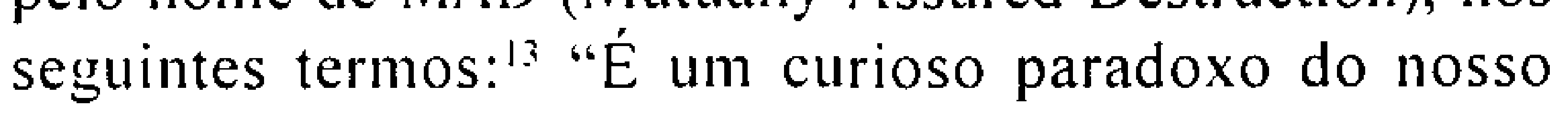
tempo que um dos fatores essenciais que fazem com que a dissuasão (nuclear) realmente funcione, e funcione bem, seja o medo subjacente de que ela poderia fracassar em caso de crise muito grave. Nestas circunstâncias, não se provoca o destino." Esta fórmula, ao mesmo tempo iluminada e enigmática, diz-nos o seguinte: para tornar a perspectiva da catástrofe dissuasiva, é preciso vê-la como um destino, mas um destino que só se realizaria devido a um erro, pelo qual nós seríamos os únicos responsáveis. É conhecida a reflexão desesperada de Albert Einstein: "Liberando o poder do átomo, nós transformamos tudo; tudo, exceto nossa maneira de pensar, e estamos caminhando em direção a catástrofes impensáveis". ${ }^{+1}$. Mututatis mutundis, a lição se aplica a nossa situação atual.

O "catastrofismo" também é criticado por visar ao "risco zero", uma vez que isto seria obviamente inatingível, e por querer impor a inversão do ônus da prova: de agora em diante caberia aos inovadores demonstrarem que seus produtos ou invenções são desprovidos de

11 Devo esta comparaçio a Catherine L amerere. (N.A.)

Bison fute-servico alternativo de informação sobre a situaçào do träfego nas rodovias francesas em feriados ou periodos de férias. Este serviço permite aos motoristas informarem-se de antemào, podendo assim desviar os congestionamentos. (N.T.)

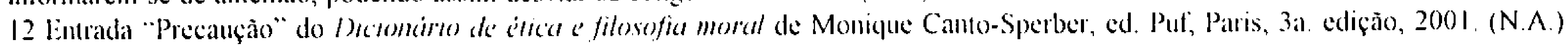

I3 BlERNARD, B. Itar aml Polmcx. New York: Macmillan, 1973. (N.A.)

It li: NATIIAN, O.; NORDIEN, H. (lids.). 1968. p. 376. (N.A.) 
qualquer nocividade - uma demonstração que seria impossível fornecer, considerando-se a filosofia das ciências de Karl Popper mencionada acima. Nossos autores contra-atacam. O risco zero é um pseudoproblema: "atrás do leitmotiv' permanente de 'o risco zero não existe', o que é evidente, esconde-se uma verdadeira recusa em aplicar seriamente o princípio da precaução, que é o único a poder racionalizar e humanizar o progresso." ( $p$. 140). A inversão do ônus da prova, por sua vez, é justamente aquilo que constitui a essência da precaução, isto não significa, porém, que seria necessário fornecer a prova da inocuidade total.

A referência a Popper, que nossos autores apresentam aos críticos do catastrofismo, parece-me não apenas inútil, mas também enganadora. Há uma maneira muito menos questionável e muito mais simples de apresentar as coisas dentro do quadro probabilista de qualquer ciência aplicada, que permite pôr bem em evidência a inversão maior que o princípio de precaução constitui em matéria de administração da prova. Vale acrescentar que esta inversão, ainda que necessária, está longe de ser suficiente para a definição de uma postura filosófica e política que esteja à altura do problema que constituem as novas ameaças.

Em matéria de estatística, não é verdade que a ausência de prova "p", onde "p" é, por exemplo, a proposição "o produto X é nocivo", seja suficiente para demonstrar "Não p" (aqui, "o produto X não é nocivo"). De maneira concisa, pode-se escrever:

\section{Nào Prova $|p| \neq>$ Prova $\mid$ Não $p \mid$}

Vamos imaginar que estejamos em dúvida quanto a uma moeda com a qual pretendemos jogar cara ou coroa: ela parece desequilibrada em favor de cara. Joga-se a moeda por três vezes seguidas e, efetivamente, ela cai todas as vezes do lado cara. Se isto fosse produto do acaso, a moeda estando realmente equilibrada, a probabilidade a priori deste resultado seria de 1/2 ao cubo, ou seja $1 / 8$, ou ainda $12,50 \%$. Por convenção, admite-se em estatística que uma probabilidade superior a $5 \%$ não é suficiente para refutar a hipótese de que o resultado seja devido ao acaso. Por que exigir $5 \%$ e não se contentar, por exemplo, com $45 \%$ ou $33 \%$ ? Talvez este limite seja em parte arbitrário, mas ele traduz a noção de "ônus da prova". Se o objetivo aqui é provar que a moeda está desequilibrada, é preciso fazer um esforço suplementar de pesquisa e de experimentação de maneira a atingir um grau de convicção "beyond a reasonable doubt", 's como se diz em inglês. No presente caso, estamos longe do resultado e será necessário admitir que não está provado que a moeda esteja desequilibrada. Seria um sofisma flagrante concluir, a partir disso, que não está provado que a moeda não esteja desequilibrada. Uma proposição pode encontrar-se na situação em que nem ela nem a sua negação estejam provadas. ${ }^{16}$ Ora, existem muitos casos em que se acredita ou se afirma que foi provado que tal produto é desprovido de nocividade enquanto que a única coisa que se pode dizer é que não se conseguiu provar a sua nocividade.

O fato de o princípio de precaução ter tomado a cena - e com que arroubo! - mostra que até recentemente, ao contrário, a ausência de prova de que uma inovação técnica ou comercial era nociva bastava para garantir que ela não o fosse. Com o princípio de precaução, exige-se então que a prova de inocuidade seja fornecida. É preciso escandalizar-se com isso? Sobre quem recai o ônus da prova? A resposta a esta questão depende da lógica da situação e dos valores da sociedade considerada. Em um processo jurídico, considera-se que entre o erro judiciário que culmina com a condenação de um inocente e aquele que conduz a libertar um culpado, é a primeira situação, de longe, a que se deve evitar. É, portanto, normal exigir que a acusação forneça, "beyond a reasonable doubt" 17 a prova de que o acusado seja realmente o culpado. O fato de que este não tenha conseguido estabelecer sua inocência não poderia substituir a prova da culpa.

Da mesma forma, o que é mais conforme ao bom senso do que, no caso em que os danos sejam potencialmente graves ou irreversiveis, considerar que é melhor errar imputando-se nocividade do que no sentido contrário? Cabe então ao inovador provar que seu produto 
não é nocivo, a ausência de provas de que ele o seja não sendo em absoluto suficiente para essa demonstração. Um estudo inglês recente sobre artigos científicos em matéria de engenharia genética mostra, contudo, que mesmo quando se pretende aplicar o princípio de precaução, comete-se o sofisma da moeda apresentado acima. ${ }^{18}$ Seria esta inversão do ônus da prova exorbitante? Não, pois, mais uma vez, ela não implica de forma alguma que a inocuidade total seja estabelecida. Ir "além da dúvida razoável", quer dizer, levar a menos de $5 \%$ a probabilidade a priori de que os resultados de experiências que parecem confirmar a hipótese de inocuidade sejam frutos do acaso, no caso da hipótese contrária ser comprovada, é uma tarefa cuja necessidade deveria ser reconhecida por qualquer espírito responsável. É necessário consagrar meios de pesquisa e de investigação suficientes para isso. Todo mundo deveria concordar pacificamente quanto a isso.

Portanto, o tipo de "catastrofismo" implicado na inversão do ônus da prova não é nada além de algo bastante razoável. Resta, porém, a acusação de que o catastrofismo, em um sentido amplo, aumentaria a responsabilidade humana de maneira "hiperbólica" e conduziria de fato à paralisia da inovação e à abstenção generalizada. Aqui também, Corinne Lepage e François Guery contra-atacam e assumem sua posição com coragem. Confundir abstenção com inação é uma inferência indevida, mostram eles. Não há ação que exprima de maneira mais elevada a liberdade do homem do que a de se fixar limites, sob forma de imperativos, de normas e de regras válidas universalmente, bem como a sua capacidade individual de agir e de observar estes limites. É por esta autolimitação que os individuos tornam-se pessoas autônomas e entram em comunicação uns com os outros. O debate democrático quanto às novas ameaças vai tratar mais e mais dos limites que as sociedades industriais deverão impor a elas mesmas, em coordenação umas com as outras, antes ou por medo que um ecofascismo aterrorizante imponha sua lei sobre o planeta.

Quanto ao "caráter global e ilimitado da responsabilidade, que contrasta com o pequeno raio de ação de nossas tarefas cotidianas" (p. 132), é pena que François Guery procure inspiração para tratar do assunto unicamente na filosofia alemã, com Heidegger, Arendt e claro, Jonas, sem esquecer, como veremos mais à frente,
Nietzsche. O contra-senso que ele comete com relação ao tema do utilitarismo o impede de abordar este assunto pelo viés do debate anglo-americano. Seria de grande ajuda para o desenvolvimento de suas idéias se ele tivesse percebido isso.

O utilitarismo, longe de ser uma política do interesse egoísta, faz parte das doutrinas morais ditas consequiencialistas. O conseqüencialismo pretende encarnar a racionalidade em ética. Seu princípio diz: "é preciso sempre visar a aumentar o bem e a diminuir o mal, globalmente, no mundo". Como o seu nome indica, ele se interessa exclusivamente pelas conseqüências dos atos e não, como a moral do senso comum, pela conformidade dos atos a normas ou regras, ou ainda pelas intenções, boas ou más, que estejam na origem deles. A filosofia moral de língua inglesa sofreu, nos anos 70, um choque que a abalou profundamente: o domínio que o conseqüencialismo exercia sobre os seus seguidores havia mais ou menos dois séculos foi repentinamente desafiado com uma força jamais vista por outra grande tradição moral, a deontologia kantiana. Foi a publicação da obra de John Rawls, A Theory of justice, a causa de toda esta agitação. Assim, até pouco tempo atrás, parecia que a relação de forças havia mudado, tão forte foi a influência do rawlsismo, e que o conseqüencialismo, em particular na sua variante utilitarista, estava, ao menos por algum tempo, relegado ao espaço reservado às velharias filosóficas. É interessante para o nosso propósito observar que é em favor, pode-se dizer, de uma reflexão sobre as ameaças que pesam sobre o futuro da humanidade que o conseqüencialismo se reorientou, mostrando que continua vivo.

Recentemente, um dos mestres do conseqüencialismo americano, Samuel Scheffer publicou um artigo importante, "Individual Responsibility in a Global Age".19 Nele, defende a tese que, se podemos conceber nossa responsabilidade na nova situação em que nos encontramos, a qual ele caracteriza como uma situação de globalização de ameaças, este conceito não pode ser fornecido senão pelo consequiencialismo. A moral do senso comum, aqui, é totalmente imprópria.

A moral do senso comum - e isso pode explicar que elementos não conseqüencialistas ocupem aqui um lugar importante - está ancorada em uma fenomenologia 
da ação que corresponde ao que foi a experiência comum da humanidade ao longo de sua história e isso até um passado recente. A experiência comum tornava evidente que: 1) os atos são mais importantes que as omissões; 2) os efeitos a curto prazo são muito mais visíveis, e portanto contam mais, que os efeitos a longo prazo; 3 ) os efeitos individuais têm mais importância que os efeitos de grupo ou os efeitos de composição.

Os traços, essencialmente não conseqüencialistas, da moral do senso comum que refletem diretamente a fenomenologia da ação ordinária são: 1) os deveres negativos têm prioridade absoluta sobre os deveres positivos; tem-se mais responsabilidade por aquilo que se faz do que por aquilo que se impede (ou não se impede) de se realizar. Não se faz mal a um inocente mesmo que esta seja a condição sine qua non para ajudar outras dez pessoas; 2) todos têm, com relação aos seus próximos, obrigações particulares e especiais que não têm para com o resto da humanidade.

Esta concepção restritiva da responsabilidade normativa tornou-se totalmente inadequada à nossa situação atual. Os deveres positivos tornaram-se tão importantes quanto os deveres negativos. A distinção entre matar por um ato individual intencional e matar por se pensar apenas em seu bem estar egoísta de cidadão de um país rico, enquanto outros morrem de fome, é uma distinção cada vez menos sustentável. Muitas ameaças que pesam sobre o nosso futuro são o resultado de um processo de sinergia de uma multiplicidade de ações individuais minúsculas das quais cada uma tomada isoladamente tem conseqüências imperceptíveis (pensemos no aquecimento do clima). A distinção entre omissão e ação perde qualquer sentido: "abstenha-se de usar seu carro para se deslocar na cidade!", diz a linguagem ordinária. Se nós obedecermos, seria isto uma "abstenção"? $\mathrm{Na}$ verdade, isto seria uma ação no sentido total da palavra e de acordo com a sua etimologia: início não causado, realização de algo radicalmente novo na rede das relações humanas etc.

O que torna o conseqüencialismo débil aos olhos da moral do senso comum é que ele não dá nenhuma importância, nem tampouco um sentido, às distinções que são tão cruciais para esta moral. O que constitui a sua fraqueza acaba, então, por tornar-se a sua força e mesmo o seu caráter de único recurso, pelo menos se forem consideradas as idéias de Scheffer.
Mas esta é uma vitória de Pirrus. As razões que explicam a necessidade do recurso ao conseqüencialismo são as mesmas que explicam sua impotência. A complexidade da cadeia causal que liga ações e conseqüências não é controlável nem no plano conceitual (fabricação de modelos, eles mesmos "complexos" com todos os traços relacionados: não integrabilidade, sensibilidade às condições iniciais, "efeito borboleta" etc.), muito menos na prática. Esta complexidade torna vã toda esperança de realizar um cálculo das conseqüências.

A conclusão de Scheffer tem um lado desesperador. A concepção normativa da responsabilidade fundada sobre a moral do senso comum é completamente inadaptada à nossa situação atual, e se há uma direção para transformá-la inteiramente é tão somente adotando-se uma postura conseqüencialista. Infelizmente, aqui também não se está a salvo. Conclusão: é a própria noção de responsabilidade que se encontra sem nenhum fundamento, ao menos no plano da ética.

Corinne Lepage e François Guery não fazem esta análise, mas em algumas belas passagens de seu livro encontra-se a evocação do que poderia constituir uma saída para o impasse. Eu gostaria de concluir tratando deste ponto.

Discutindo com sua colega sobre a diferença entre prevenção e precaução, François Guery diz, o que não deixa de surpreender, que: "A precaução é a base não da pura ignorância, mas da suspeita muito verificável, da quase-certeza..."(p. 51). Por que a surpresa? Porque se acreditava, talvez um pouco levianamente, que a precaução, da mesma forma que a prevenção, era uma atitude face ao incerto, não face à certeza! No próprio relatório Kourilsky-Viney percebe-se um sentimento de obrigação em afastar esta interpretação quando se escreve: "Pensa-se freqüentemente que os riscos potenciais são pouco prováveis, e eles são assimilados inconscientemente a riscos comprovados cuja probabilidade tornase mais fraca à medida que estes riscos são controlados de maneira eficaz. Isto é (...) inexato (...) ....) Os riscos potenciais, a despeito de seu caráter hipotético, podem ter uma probabilidade de realização elevada". ${ }^{20}$

A precaução responderia então à possibilidade do muito provável. Atualmente, nada permite afastar a hipótese de que o aquecimento climático provoque seguramente uma elevação da temperatura numa escala catastrófica até o final do século. Sob pena de confusão 
fatal, este tipo de proposição deve ser analisado distinguindo-se cuidadosamente dois tipos de modalidades: a possibilidade e a verossimilhança. No relatório KourilskyViney insiste-se com propriedade quanto a esta distinção. Considero, entretanto, que uma outra confusão modal se insinua aqui. Com relação às novas ameaças, não é do "quase-certo" ou do "muito provável" que queremos falar, mas sim do caráter inevitável destas ameaças. Daí a referência sistemática ao destino e à fatalidade. É possível que a catástrofe esteja inscrita no futuro. Ora, isto longe de constituir uma visão pessimista de nossa situação, representa talvez nossa única possibilidade de salvação. É pelo fato de nos fixarmos nesta possibilidade que encontraremos, talvez, os meios de fazer com que o inevitável não se produza.

O mérito de François Guery e de Corinne Lepage é de levar a sério a ética do futuro, ou do porvir que nos propõe Jonas. Esta ética não é conseqüencialista. A razão profunda pela qual ela não o é tem a ver com a direção do tempo. O conseqüencialismo vai do presente para o futuro, exatamente como indica a etimologia de "conseqüência": aquilo que acompanha vindo em seguida. A "ética do porvir". esta, olha o presente, o nosso presente, do ponto de vista do futuro. Esta inversão é o que cria, no plano metafísico, a perfeita especificidade, a originalidade profunda e a beleza da ética proposta por Jonas. Eis o que ele escreve sobre a heurística do medo: "O que pode servir de bússola? A antecipação da própria ameaça! É somente nos primeiros raios da tempestade da ameaça que está por vir, na aurora de sua amplitude planetária e na profundeza dos problemas humanos, que podem ser descobertos os princípios éticos a partir dos quais é possível deduzir as novas obrigações correspondentes ao novo poder". ${ }^{21}$
Para pensar este enigma a partir de um sinal que nos viria do futuro, François Guery tem a excelente idéia de se referir a uma das maiores obras da filosofia moral, $A$ Genealogia da moral, de Nietzsche. Nesta obra, o filósofo alemão procura a origem dos conceitos morais na palavra que o devedor oferece como garantia ao credor em troca de seu empréstimo. Esta palavra envolve a ação futura, a restituição do empréstimo. "A formação dos conceitos morais, escreve brilhantemente François Guery, tem, portanto, uma raiz na continuidade da vontade através do tempo. (O homem) é 'o animal que pode prometer'. Esta inovação moral marca toda a história da humanidade, que domina o tempo pela responsabilidade.", (p. 30).

O que vale para a promessa vale também, mutatis mulandi, para a ameaça. Nos dois casos, a vontade se fixa sobre o evento futuro, num caso para realizá-lo, no outro para afastá-lo. É, portanto, algo que ainda não adveio que serve de alavanca para a vontade responsável. Para definir esta inversão temporal, François Guery atribui a Nietzsche esta expressão admirável: "a memória do futuro". É lamentável para Nietzsche que esta não tenha sido a expressão que ele empregou: ele fala somente de "memória da vontade",22 em que se perde justamente o sentido da inversão temporal. Pouco importa: tem-se aí, sem dúvida, o ponto de partida de um pensamento à altura da discussão.

Concluindo, encontram-se aqui, portanto, muitos ingredientes de qualidade que poderiam servir de prolegômenos para uma defesa razoável da postura catastrofista. Se os escritores tivessem se dado o trabatho de escrever um livro de verdade, eles poderiam, talvez, ultrapassar o estágio inicial em que suas conversas dispersivas os deixaram. O essencial da tarefa permanece por fazer, mas a orientação é boa.

21 le Primcipe Respomsabillki, op. cil.p.16; grifo meu. (N.A.)

22 l:diçòes Gallimard, páginas 251-252. Ocone que nos trabalhos fue eu conduzo há 15 anos sobre os fiundamentos metafisicos da filosofia da açào, em particular da filosofía da promessa, do envolvimento, mas também da ameaça e da dissuasào, eu forjec a expressào "memória do futuro", ou ainda, "traço do futuro". Quando eu li o sr. Guers, minha primeira reaçào foi pensar que, inocentemente, eu havia reinventado o termo de Nietzscle. Idéa esta bastante razoável, já que a Genealogia da Moral foi meu livro de cabeceira durante muito tempo. Consultando o meu exemplar, descobri que Nictzsclue nào utilizou a expressào em questào. Meu espanto se translormou em franco riso quando eu li a seqüencia do lexto de M. Guery: "lambém se dirá "projeto". Ora, eu chamei a metafisica que subentende esta inversào temporal de o "tempo do projeto". Teria M. Guery me confundido com Nietzscle?" (N.A.) 